\title{
Calcium Corrected Measurement
}

National Cancer Institute

\section{Source}

National Cancer Institute. Calcium Corrected Measurement. NCI Thesaurus. Code C119272.

The determination of the amount of the calcium corrected in a biological specimen. 